\title{
Microwave Assisted Manufacturing and Repair of Carbon Reinforced Nanocomposites
}

\author{
Edward D. Sosa, ${ }^{1,2}$ Erica S. Worthy, ${ }^{3}$ and Thomas K. Darlington ${ }^{4}$ \\ ${ }^{1}$ Texas State University, San Marcos, TX, USA \\ ${ }_{2}^{2}$ Johnson Space Center Engineering, Technology and Science (JETS) Contract, Jacobs, Houston, TX, USA \\ ${ }^{3}$ National Aeronautics and Space Administration, Johnson Space Center, Houston, TX, USA \\ ${ }^{4}$ nanoComposix, San Diego, CA, USA
}

Correspondence should be addressed to Edward D. Sosa; edsosall@gmail.com

Received 11 June 2016; Revised 17 August 2016; Accepted 30 August 2016

Academic Editor: Yanqing Yang

Copyright (C) 2016 Edward D. Sosa et al. This is an open access article distributed under the Creative Commons Attribution License, which permits unrestricted use, distribution, and reproduction in any medium, provided the original work is properly cited.

\begin{abstract}
We report a composite capable of advanced manufacturing and damage repair. Microwave energy is used to induce thermal reversible polymerization of the matrix allowing for microwave assisted composite welding and repair. Composites can be bonded together in just a few minutes through microwave welding. Lap shear testing demonstrates that microwave welded composites exhibit $40 \%$ bond strength relative to composites bonded with epoxy resin. Double cantilever beam testing shows $60 \%$ recovery in delamination strength after microwave assisted composite repair. The interfacial adhesion and composite repair after microwave exposure are examined by X-ray computed tomography. The microwave processing is shown to be reproducible and consistent. The ability to perform scalable manufacturing is demonstrated by the construction of a large structure from smaller components.
\end{abstract}

\section{Introduction}

Composites offer an immense potential for reducing energy expenditure during the operation of systems composed of these materials due to their light weight. This is of significant interest to the aerospace and transportation sectors since composite materials can lead to the production of more fuel efficient aircraft and vehicles. Composites are ideal candidates for structural components in aircraft, automobiles, trains, and space exploration systems since their mass savings translate directly into lower operational cost. Unfortunately, the realization of operational savings resulting from lower energy expenditure has been overshadowed by cost associated with composite manufacturing and the concerns of damage tolerance. Thermal processing, precision machining, bonding, and low damage tolerance all result in increased cost of the manufacturing, assembly, and maintenance of composite structures.

Conventional heating methods used for the production of composites can drive up manufacturing cost as a result of the inefficient heat transfer processes involved in the curing of these materials. Autoclave curing, especially of large parts, is uneconomical since much of the heat is lost to the surrounding environment and the conduction of heat within the part is very inefficient due to the low thermal conductivities of polymeric materials. Furthermore, improper curing can significantly affect the composite properties. Microwaves, which are widely used for communications, have found potential application in the heating and processing of polymer based materials [1-3]. Microwave heating, which is volumetric since it occurs at the molecular level, can consume 100 times less energy than conventional heating [4] thus leading to faster and more efficient curing. Microwave heating, therefore, has the advantages of reduced processing times and greater energy savings during composite production [5]. In addition to economical curing, microwaves also offer the possibility of uniform and complete heating of parts regardless of their geometries [6]. This can be a tremendous benefit since large, thick, and nonuniform parts are not very suitable for autoclave curing because undesirable thermal gradients within both oven and materials can make it difficult to ensure uniform and complete curing. If the microwave field with 
the chamber is uniform heating gradients will be minimized. Ideally, a rotating platform will provide uniform exposure. Microwave processing can therefore provide more effective and efficient curing, thereby leading to a reduction in the time and cost of composite manufacturing.

Another promising capability of microwaves is their potential use for bonding or welding of polymer materials. Polymer composites are generally joined through the use of adhesives or mechanical fasteners. These methods can require extensive surface preparation for adhesive bonding and can result in localized stress fields around machined areas necessary for the placement of fasteners. Polymer welding is seen as an alternative to the aforementioned bonding methods. Techniques such as hot plate, ultrasonic technique, induction, laser, friction stir, and electromagnetic welding have been proposed [7, 8]. Microwave welding has an advantage over the many other forms of welding because complex three-dimensional structures can be configured since the entire component can be irradiated simultaneously [9]. Unfortunately, most polymers have poor microwave absorption properties thereby requiring the use of microwave adsorbent additives. Materials with low-to-medium dielectric loss factors require no microwave absorber materials while materials with high dielectric loss factors require absorbing materials at the interface [10]. Carbon nanotubes (CNTs) are an ideal microwave absorbing material as they readily absorb the energy and convert it into heat due to electronic losses within the CNT structure [11-13]. Since microwave absorption is a bulk process facilitated by the CNTs, adequate dispersion is required to reach the percolation threshold which will minimize any thermal gradient within the composite. Carbon nanotubes can provide a means to locally heat the interface of two adjoining surfaces allowing for microwave welding of individual parts. Microwave induced heating occurs only at the interface resulting in lower power consumption since the entire material does not need to be heated. The exceptional strength of CNTs can also provide additional reinforcement of the weld joint through bridging across the interface. Several studies have demonstrated the ability to use CNTs for microwave welding of thermoplastic, thermoset, and nonpolymeric materials both efficiently and effectively [14-18]. The use of microwaves for the welding of composite materials can lead to new developments in composite technology particularly in the area of additive manufacturing.

Self-healing composites [19-21] are an area of extensive research as self-repairing materials can help improve the damage tolerance of composites. Extrinsically healable composites utilize external stimuli such as heat, electromagnetic radiation, or pressure to facilitate repair. Composites that can be internally repaired through the use of heat could utilize microwaves as the heating source. Previous work has shown that microwaves can be used to rapidly heat thermally healable composites consisting of a bismaleimide tetrafuran (2MEP4F) matrix [22, 23]. Microwave heating is demonstrated to be an efficient and effective method of heating. An additional advantage of using microwaves as the heat source as opposed to electrical resistance heating is the ability to locally heat the material. Localized heating provides healing only of the area to be repaired thereby not subjecting the entire structure to softening which could jeopardize the structural integrity if under load. The thermal energy supplied by the microwaves allows reversible Diels-Alder chemistry within the bismaleimide tetrafuran (2MEP4F) matrix that facilitates the healing through polymer mobility. Since composite welding is also facilitated by polymer mobility it only stands to reason that microwave assisted bonding of these composites should be possible. The $2 \mathrm{MEP} 4 \mathrm{~F}$ resin system that constitutes the matrix of these composites is the material that provides the means for composite welding and repair. Thermal reversible crosslinking between the furan and maleimide groups of the polymer allows for mobility within the matrix when heat is applied. The mobility results in the ability to bond matrix materials across the damage site or welding interfaces. The carbon nanotube additive merely facilitates heating through its microwave absorption property. We report preliminary microwave welding experiments on 2MEP4F carbon fiber composites.

\section{Experimental}

Composite panels were fabricated using multiwall carbon nanotubes (MWCNTs) deposited onto carbon fibers followed by infiltration with a bismaleimide tetrafuran (2MEP4F) resin. Carbon fibers were spray coated using a dispersed solution of MWCNTs as previously reported [20]. Unidirectional carbon fiber composites were then fabricated by custom resin transfer molding of the $2 \mathrm{MEP} 4 \mathrm{~F}$ resin $[24,25]$. This procedure was used to fabricate six-ply unidirectional composite panels measuring $10 \mathrm{~cm} \times 10 \mathrm{~cm}$. A total of five panels were fabricated of which one panel had a Teflon sheet insert at the midplane of the composite; the $5 \mathrm{~cm} \times 10 \mathrm{~cm}$ Teflon insert spanned half the area of the panel. This particular panel was used for double cantilever beam testing in which the insert provided a simulated crack in order to measure delamination properties. The other four composite panels were used for lap shear testing. All the fabricated panels were then dryly cut into approximately 1 in. $\times 4$ in. rectangular pieces using a mill.

Microwave processing of composites was accomplished using a Microwave Research and Applications Inc. BP-111 Microwave Processor which operates at $2.45 \mathrm{GHz}$ and has variable power up to $1000 \mathrm{~W}$. The microwave processor is equipped with the True-To-Power power control system that allows sample temperature regulation through power adjustment of the magnetron source. The oven was modified to allow continuous monitoring of the sample thermal profile. A FLIR A35SC infrared camera is mounted on a bored opening on the top of the microwave processor chamber. A wire mesh grid is placed on the inside of the opening while a germanium window was placed outside that opening to prevent microwaves from escaping. This design allows for real-time thermal imaging of the sample under microwave exposure. Fixtures fabricated in-house out of Mylar block allowed pressure clamping of composite panels during microwave welding and repair. Two sets of fixtures were fabricated, one with a circle of 1-inch diameter bored at the midpoint of the 


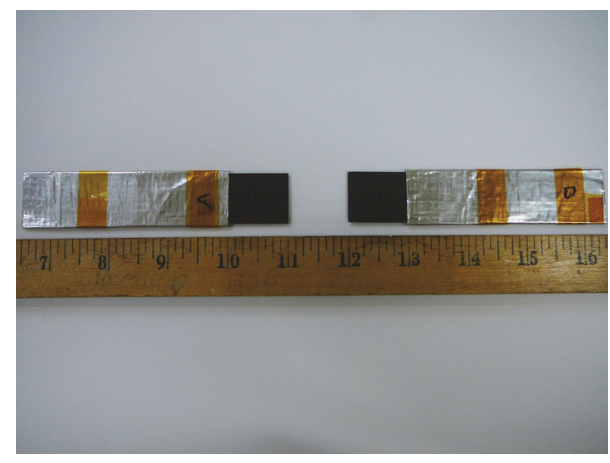

(a)

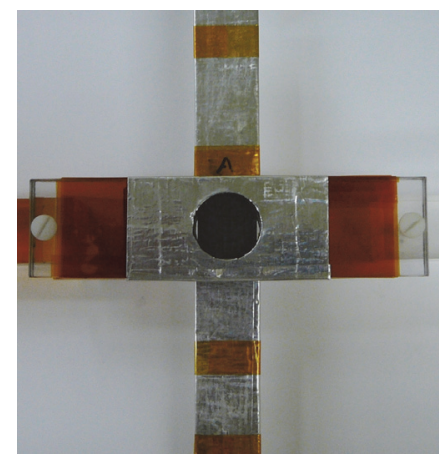

(b)

FIGURE 1: (a) Lap shear test specimens prior to microwave welding shows metal sleeves used to expose only bonding area to microwaves. (b) Clamping fixture with 1-inch-diameter hole bored into Mylar blocks to try to simulate a focused microwave source. Clamp set 2 consisted of Mylar blocks without hole in the center and with no metal tape covering of blocks.

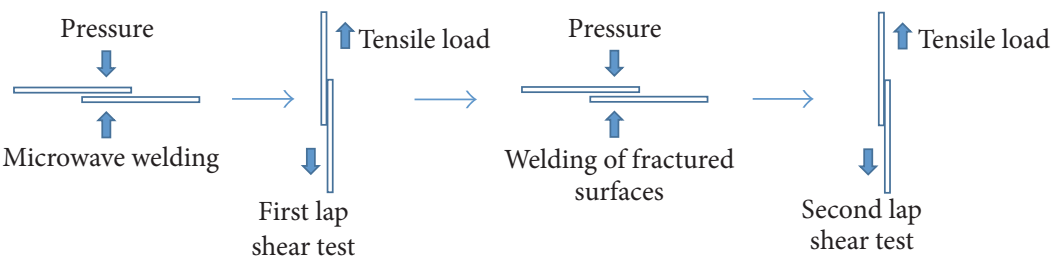

Figure 2: Lap shear testing schematic. As-manufactured composites are cut to ASTM defined dimensions. Panels are overlapped over a 1inch-by-1-inch area and held in place by clamps. The panels are heated by microwaves to initiate welding and the test. After testing welding is repeated to demonstrate reproducibility.

6-inch-long rectangular block, with the other being a solid 3inch block. The 6-inch blocks were masked with metal tape to try to simulate a focused microwave source. The pressure between the blocks was applied by nylon screws. Only the area to be welded or repaired was exposed to microwaves. The rest of the test specimen was covered with a sleeve made of metallic tape to prevent heating of that portion of the composite (Figure 1(a)). The sleeve had a Kapton tape inner liner to prevent arcing between carbon fiber and metal or fusing of the sleeve to the composite.

Lap shear testing was performed to determine the interfacial bond strength of microwave welded composite relative to adhesively bonded composites. A schematic of the experimental test plan for lap shear testing is shown in Figure 2. Testing was conducted in accordance with ASTM D5868. Test specimens were of the length and width specifications as defined by the standard; however, the thickness of $1.0 \mathrm{~mm}$ was below the nominal value of $2.5 \mathrm{~mm}$. The thickness of the specimens was limited by the mold used to fabricate the composite panels. All other standard requirements were met. Lap shear test specimens consisted of two of the rectangular pieces bonded across a 1-inch-by-1-inch overlap area. A total of seven lap shear test specimens were prepared. Six were made by microwave welding of the bond area, while the reference test specimen was bonded using a two-part 3M Scotch-Weld ${ }^{\circledR}$ 2216B/A epoxy adhesive. This adhesive was also used to bond a set of one-inch glass fiber grips on each end of the test specimens after the microwave welding and epoxy bonding was performed. Tests were conducted on MTS Insight load frame using a $2000 \mathrm{lb}$ load cell.

Double cantilever beam (DCB) tests were conducted to determine the retention in delamination strength after microwave assisted composite repair. The panel fabricated with a 13-micron-thick Teflon insert was used for these tests. Similar procedures as outlined in ASTM D5528 were followed with the exception that the length was below the specified five inches. The length of the specimens was limited by the mold used to fabricate the composite panels. Piano hinges were mounted with epoxy adhesives onto the panel sides where the insert was placed to allow pulling apart of the panel. Prior to testing, the initial crack initiation point for each sample was marked with silver ink by imaging the side of the sample under a Zeiss Discovery V20 Stereomicroscope. Test samples were pulled apart using the same MTS Insight load frame. Crack propagation was monitored with a video camera during DCB testing and was also measured afterwards under the stereomicroscope and by X-ray computed tomography.

Microwave processed specimens were analyzed to examine the effectiveness of welding and repair, as well as any damage induced by microwave exposure. Composites were characterized after cutting in order to identify any pre-microwave processing damage that could be attributed to composite manufacturing or cutting. X-ray computed tomography (CT) was used for inspection of the interfacial bonding at the weld, internal composite damage, and damage repair. 


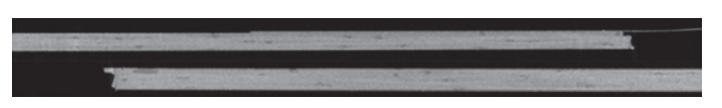

(a)

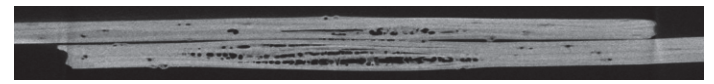

(b)

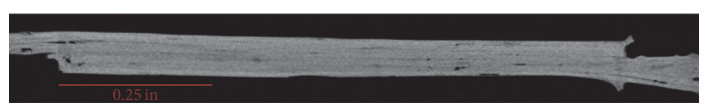

(c)

FIGURE 3: X-ray computed tomography images of composite panels (a) after cutting of fabricated panels, (b) after first microwave weld cycle with clamp 1, and (c) after second, improved microwave weld cycle with clamp 2. As-fabricated samples had low internal defect concentrations. The first weld cycle shows low interfacial bonding between panels as well as high porosity due to internal voids resulting from rapid thermal expansion and nonuniform pressure. Second weld cycle exhibits better interfacial bonding and repair of internal damage; however, some regions in some regions throughout the thickness still showed incomplete bonding.

\section{Results}

Prior to microwave welding, composite panels were inspected by X-ray CT to detect whether any defects or damage was induced by the cutting of panels. CT scans provided 3D imaging of some regions throughout the thickness of composite from each direction allowing visual inspection of any significant cracks or voids within the samples. All composite panels were paired, labeled, and color coded (green, red, yellow, and orange) to keep track of the faces and sides that were to be bonded so that subsequent CT scans always monitored the same locations. CT scans of the double cantilever beam samples were used to visually identify crack propagation and repair; therefore, pretest analysis was conducted on these samples.

The first set of lap shear test samples (Samples 1-3) were prepared by microwave welding using the clamp fixtures with 1-inch diameter cut out (Figure 1(b)). This first set consisted of three samples that were heated to the required temperature $\left(\sim 90^{\circ} \mathrm{C}\right)$ for the occurrence of bond dissociation between the furan and maleimide groups. This temperature was held for approximately 3 minutes to allow welding to take place. Thermal imaging of the composite welding showed that in some panels the edges heated more rapidly with heat progressing inward until eventually the 1 inch $\times 1$ inch welding area reached thermal equilibrium. It was also observed that arcing occurred along the edges of these samples and at times between the samples. Severe arcing resulted in damage to the composite exposing some of the carbon fibers along with decomposition of the polymer matrix. CT analysis of the welded composite panels showed that internal damage was induced by arcing effects or rapid heating resulting in void formation (Figure 3(b)). It is possible that prestress exists within the composites during microwave welding, most likely at defect sites associated with manufacturing or machining of the composite structure. Another internal stress that can exist during microwave processing is thermal stress induced by rapid or nonuniform heating. These stresses are what likely result in the blistering observed in CT data. CT analysis also showed that the interfacial bonding across the weld area was poor. The pressure applied by the clamps will influence the weld; unfortunately due to safety concerns strain gauges were not bonded to the test specimens because it was not known how they would react to microwaves. Lap shear tests supported CT analysis since the microwave weld strength was only $10 \%$ of the strength of the epoxy bonded composite. The value of $10 \%$ is established by taking the ratio of the ultimate tensile load of the best welded composite to epoxy bonded composite. It was concluded that the open area of the $1^{\prime \prime}$-diameter hole did not provide sufficient pressure across the bonding area to facilitate polymer mobility across the interface of composites. The clamping devices were simplistic and a more sophisticate design of clamps that enables controlled pressure will provide more reliable welds.

In order to provide a more uniform pressure across the welding area the solid 3-inch clamp was used for subsequent microwave processing. Samples 1-3 were rewelded in similar manner followed by CT inspection before conducting the second set of lap shear tests. During the microwave processing, in situ thermal imaging displayed more uniform heating and the absence of arcing during exposure. CT imaging showed that the rewelded composites had greater interfacial bonding and underwent damage repair (Figure 3(c)). Previous voids within the composite were eliminated after a second microwave exposure displaying the healable nature of the composites. A second set of lap shear test specimens (Samples 4-6) were welded to establish the reproducibility and consistency of the welding process. Similar observations were observed in both welding characteristics and mechanical properties.

After the rewelding of Samples 1-3, the percentage of strength relative to the epoxy bonded composite increased from $10 \%$ to $40 \%$. While the rewelded composites exhibit higher retention in strength at the weld, analysis of CT scans across the entire weld thickness identified regions where gaps still existed between the panels. This indicates that complete bonding between the two welded panels was not fully achieved and translated into a lower-than-desired bond strength of at least $75 \%$. It is expected that greater strength can be accomplished if complete bonding can be achieved. Future work will investigate the use of a reinforcement agent such as a wire mesh or thin sheet of nanotube "Bucky" paper. Since Diels-Alder chemistry can occur between the CNT side wall and the polymer matrix [26], it is believed that direct bonding between CNT and matrix may have significant improvement in the weld strength. In any case, welding was shown to be reproducible with comparable or better weld strengths after each welding cycle. 


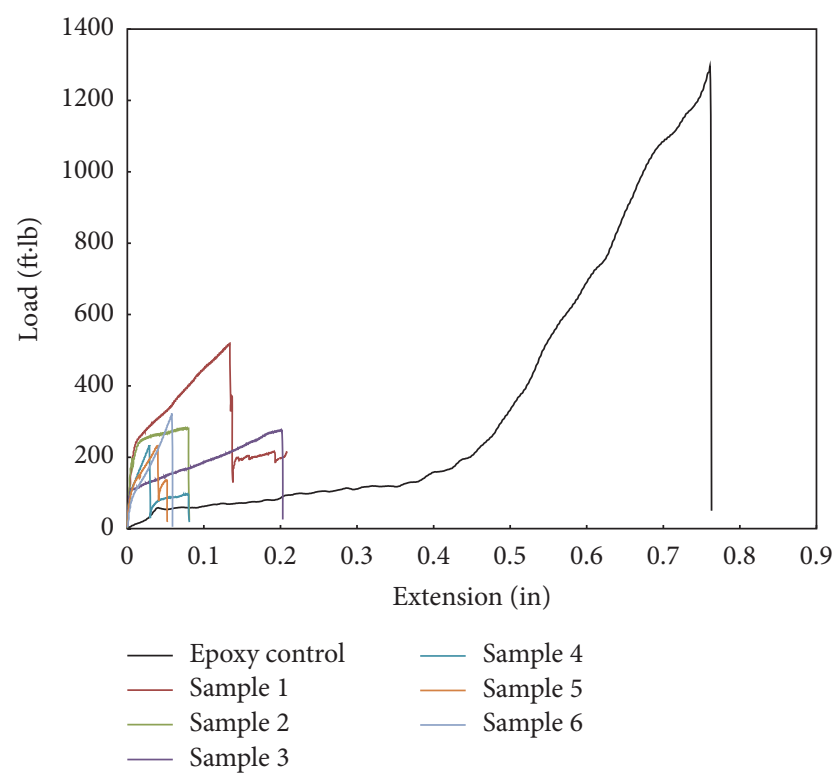

FIGURE 4: Lap shear tests of microwave welded composites relative to an epoxy bonded control sample. Microwave welded composites exhibit higher modulus but lower ultimate strength. Welded composites Samples 1, 4, and 5 exhibit sudden decrease in load followed by continued load increase which is attributed to partial shear of the weld plane.

Figure 4 shows the lap shear test results of all six welded samples relative to the epoxy control. The curves show similar behavior among the samples. First, the modulus portion of the curves indicate that the welded composites exhibit higher stiffness than the epoxy bonded composite. Second, the lap shear curves show a region of yielding with increased load followed by failure. Finally, some composites exhibit sudden load decrease followed by load recovery. The observation of higher stiffness is attributed to the intermolecular bonding between the polymers at interface. The bonding at interface in the welded composites occurs because of crosslinking between furan and maleimide groups within the 2MEP4F thermoset resin. It is this reversible crosslinking that allows the Diels-Alder chemistry which accounts for the thermally reversible polymerization and thus welding. The interfacial adhesion within the epoxy bonded composite is not directly known but could be due to polar forces or direct chemical bonding between polymer chain groups of the epoxy and $2 \mathrm{MEP} 4 \mathrm{~F}$ resins. In either case, it is reasonable to expect the intermolecular bonding between the 2MEP4F interfaces is stronger than the intermolecular bonding between the epoxy and 2MEP4F. Table 1 shows the mechanical properties for both $2 \mathrm{MEP} 4 \mathrm{~F}$ and epoxy resins. While there is no documented comparison between the shear strengths of the two systems, the values obtained by lap shear testing of the epoxy bonded composites are comparable to range of values listed in Table 1. The values of $6.2-11 \mathrm{MPa}$ correspond to different plastic materials bonded with the 2216B/A epoxy and are in good agreement with the approximately $1300 \mathrm{psi}$ obtained in our test. For homogeneous isotropic materials a simple relation exists between elastic constants; namely,
TABLE 1: Mechanical properties of the thermal reversible 2MEP4F and the epoxy resin used for bonding of lap shear test samples.

\begin{tabular}{|c|c|c|c|}
\hline \multicolumn{4}{|c|}{ Mechanical properties of $2 \mathrm{MEP} 4 \mathrm{~F}$ and epoxy resin } \\
\hline & & 2MEP4F & 2216B/A epoxy \\
\hline $\begin{array}{l}\text { Compression } \\
\text { testing }\end{array}$ & $\begin{array}{l}\text { Young's modulus } \\
\text { (GPa) }\end{array}$ & $4.14^{\mathrm{a}}$ & \\
\hline \multirow{2}{*}{$\begin{array}{l}\text { Overlap shear } \\
\text { testing }\end{array}$} & $\begin{array}{l}\text { Shear strength } \\
(\mathrm{MPa})\end{array}$ & & $6.2-11.0^{c}$ \\
\hline & $\begin{array}{l}\text { Shear modulus } \\
\text { (MPa) }\end{array}$ & & $1500^{c}$ \\
\hline
\end{tabular}

$\overline{{ }^{a} \text { Reference [27], }{ }^{\mathrm{b}} 3 \mathrm{M} \text { Scotch-Weld technical data sheet, and }{ }^{\mathrm{c}} \text { ASTM D1002. }}$

$E=2 G(1+v)$. In this equation $E$ is Young's modulus, $G$ is the shear modulus, and $v$ is the Poisson Ratio. If $v$ is small, then $E=2 G$. The $3 \mathrm{M}$ technical data sheet does not provide any information on Young's modulus or Poisson Ratio of the epoxy. Making the simple approximation that Young's modulus is twice the shear modulus would indicate that the 2MEP4F has higher stiffness. While this assumption is not verified by empirical testing in our laboratories, the approximation supports our observation. Future tests will make direct comparison of such mechanical properties.

As the load increases, yielding occurs due to stress transfer into the matrix region near the interface. Yielding continues with increased load until ultimate failure occurs. After failure, close observation of the composite panels showed delamination within the panels since carbon fibers could be seen in areas that appeared to be abraded. One of the welded composites exhibited cleavage along the fiber direction a distance away from the weld area. It is proposed that failure occurs within the matrix as opposed to purely at the interface. It is believed that the microwave induced voids observed in the CT analysis are the point of failure. The stress transfer eventually exceeds the strength in these damaged regions resulting in break of the weld. It is believed that these abraded regions are where the most effective welding occurred within the microwave processed composites but are also an area of higher defect concentration. This delamination effect was observed in both the welded and epoxy bonded composite. The final feature observed in some of the welded composites is a sharp decrease in load with ensuing load recovery. This is attributed to shear slip that occurs at bonded regions of the interface. As noted previously, CT scan showed areas that were not bonded. As load is applied to the interface some of these weld regions shear resulting in the sharp decline in load but not total failure. Therefore, the lowerthan-desired weld strength can be attributed to incomplete interfacial bonding and internal defects. It is believed that complete bonding across the weld interface and elimination of microwave induced defects will result in bond strength comparable to that of the epoxy adhesive.

Double cantilever beam testing is shown in Figure 5. Although specimen dimensions were slightly below the ASTM D5528 specifications, DCB testing can still provide a good measure of delamination recovery and therefore the healing effectiveness of microwave processing. With the exception of Sample 2 before microwave healing, all curves 


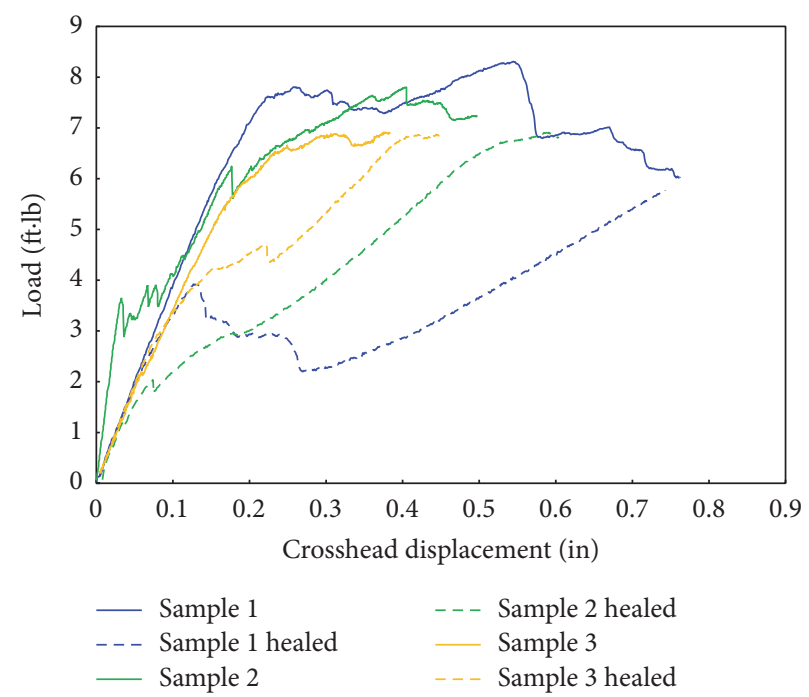

FIGURE 5: Double cantilever beam testing of composite samples before and after microwave processing (healed). Post-microwave processing samples exhibit incomplete healing as indicated by lower load tolerance before delamination onset. The continued increase in load with crosshead displacement indicates greater tear resistance.

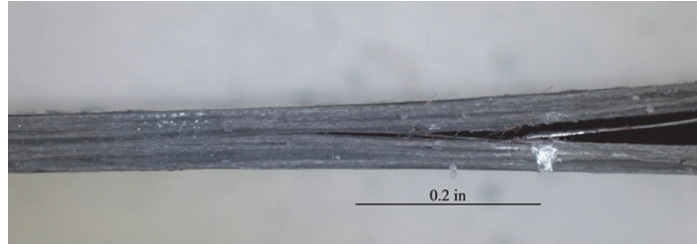

(a)

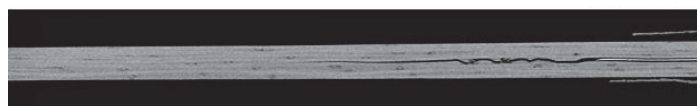

(c)

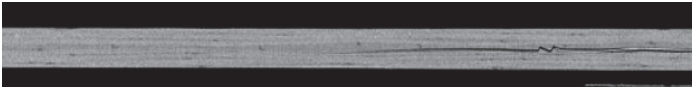

(b)

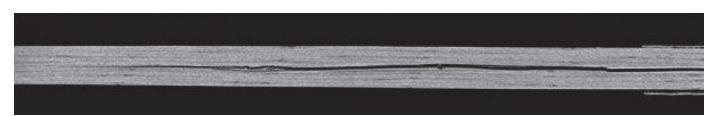

(d)

FIGURE 6: Inspection of crack propagation length after DCB testing of as-fabricated composites: (a) optical microscopy of sample, (b) CT analysis of Sample 3, (c) CT analysis of Sample 2, and (d) CT analysis of Sample 1. Lengths of cracks correspond to crosshead displacement and crack deflection is clearly visible.

exhibit similar slopes prior to delamination. This is to be expected since all the samples are fabricated from the same materials and are cut from the same manufactured panel and should therefore have the same stiffness. The difference in Sample 2 before microwave processing is likely to be attributed to the grips or piano hinges. Aside from this difference, the curves before and after microwave healing display similar features. The first feature is that the crosshead extension corresponds directly to the length of crack propagation. Figure 6 shows the crack lengths measured after DCB testing by optical microscopy and CT analysis. It is clearly evident that the crack length tracks identically with the crosshead extensions in the DCB curves. The explanation for differences in crack propagation under similar load is that they may be attributed to lower residual stresses, higher degree of crack deflections, or crack bridging by CNTs. The second feature observed in the DCB curves is the onset of delamination that occurs at lower loads after microwave assisted repair of the initial cracks that is shown in Figure 7. This is to be expected if complete healing of the crack is not achieved. For each sample, the load values at the onset of delamination before and after microwave processing were used to calculate the repair efficiency. The onset is established as the point at which the load no longer increases and begins to plateau followed by a decrease in load. Samples 1 and 2 showed approximately $30 \%$ recovery while Sample 3 showed $60 \%$ recovery. The final feature common to the post-microwave processing curves is the increase in load after delamination onset. It is not fully understood what contributes to the steady increase in load after delamination onset; however, this would tend to indicate better tear resistance. It could be possible that fiber or CNT bridging results after microwave exposure. Previous work on our composites has indicated that the possibility exists that Diels-Alder chemistry could occur between the polymer resin and the CNTs due to localized heating of the CNTs during microwave exposure [22]. If bridging or CNT bonding to 

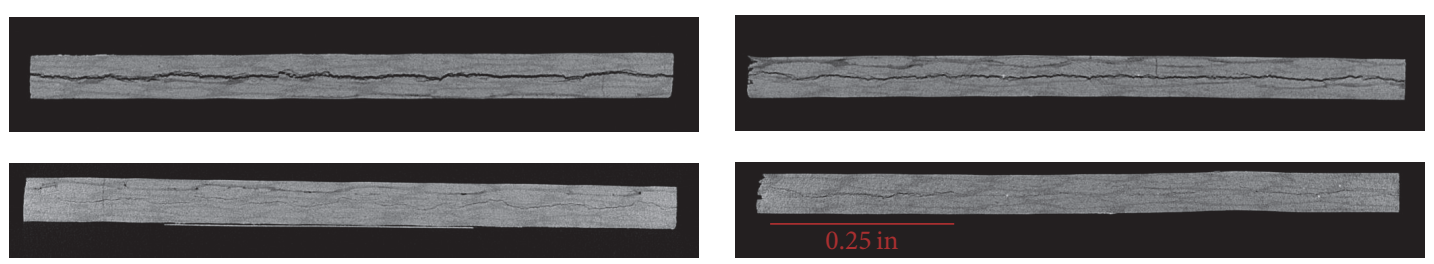

(a)

(b)

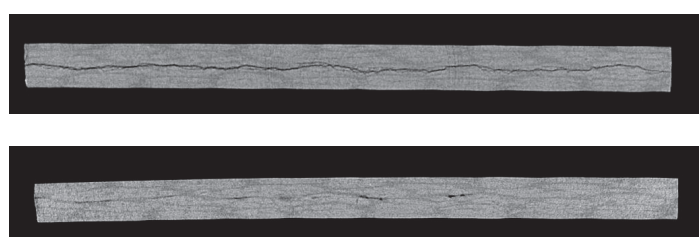

(c)

Figure 7: CT scans of composite panels before and after microwave assisted repair of delamination in (a) Sample 1, (b) Sample 2, and (c) Sample 3. It is observed that complete healing of the delaminated surface is not achieved through the entire thickness of the composite panel.
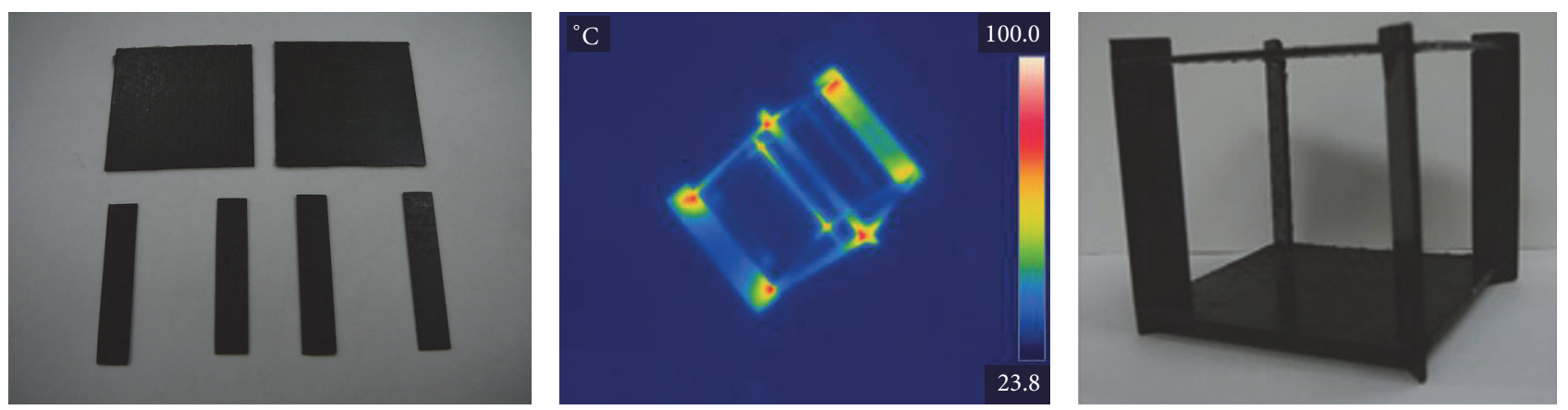

FIGURE 8: Demonstration of potential advanced manufacturing through microwave welding of a larger structure from small composite components. In situ thermal imaging during microwave exposure shows rapid localized heating at the weld points.

the matrix is occurring it could explain the observed steady increase in load after delamination onset. Regardless of the explanation, the fact that healing can be achieved and that delamination resistance maybe occurring is promising for improved damage tolerant composites.

To demonstrate that microwave welding of these composites can lead to advanced manufacturing, a larger structural architecture was constructed from small components. Smaller rectangular and square pieces were machined to allow mating of pieces. The structure was loosely assembled and placed in the oven and then exposed to microwaves with as little as 40 Watts. Thermal imaging during microwave processing shows rapid localized heating of the composite interfaces (Figure 8). The temperature at the weld joints is higher because of higher microwave absorption of exposed carbon nanotubes and fibers. It is possible that electronic losses at the interfaces may also contribute to this rapid localized heating. Previous work with damaged composites exposed to microwaves shows similar observations [23]. Temperature at the weld joints reached above $90^{\circ} \mathrm{C}$ in less than 10 seconds and the structure was heated for a oneminute period of time after which it was allowed to cool for one minute. All but one of the contact points fused together even without the application of external forces or clamping. The strength of the weld points was not measured; however, excessive pulling by hand did break the welds. While the welds are not strong (in large part because no force was applied during the weld), the concept of 3D welding through the use of microwave is demonstrated. Forward work will involve improving weld strength of these adjoining structures. This demonstration shows promise for the ability to weld larger structures from small components which can lead to an advanced manufacturing technique that can be more cost and time effective.

It is expected that several factors will influence the welding efficiency and strength at the joints. The welding efficiency may be influenced by the heating time and pressure applied at the joint. These two factors will influence the degree of bonding as they directly affect the extent of repolymerization and polymer mobility across the interfaces. The microwave power and heating temperature have minimal influence on the welding process. The microwave system only has to supply enough power to reach the target temperature of $100^{\circ} \mathrm{C}$ to initiate repolymerization. The weld strength will 
be influenced by several factors including thermal gradients, pressure, heating time, defects, and additional reinforcement. Variations in temperature or pressure across the weld joint may lead to inconsistent bonding at the interface. Insufficient heating time will cause incomplete repolymerization. Defects such as voids will lower the weld strength. Finally, the introduction of additional reinforcement such as a wire mesh or chopped fibers will improve strength.

\section{Conclusion}

The ability to use microwave energy to weld and repair carbon fiber composites has been demonstrated. The incorporation of carbon nanotubes into the carbon fiber composite provides the mechanism for microwave absorption that allows heating of the thermal reversible polymer that comprises the matrix. The reversible chemistry of the polymer resin system is utilized to weld and repair composites. Lap shear testing shows higher initial stiffness of composite welds as compared to an epoxy bonded composite which is attributed to greater intermolecular bonding of the interfaces and to the high modulus of the polymer itself [25]. Microwave welded composites exhibit $40 \%$ of the bond strength of the epoxy welded composite. Double cantilever beam testing was used to measure microwave assisted repair of delaminated composites. Tests show up to $60 \%$ recovery in delamination strength after microwave processing. Visual inspection of some regions throughout the thickness weld and repair by $\mathrm{X}$ ray computed tomography shows incomplete welding across the bonding interface and partial healing of delaminated surfaces. It is expected that weld strengths on the order of epoxy adhesive strengths and full repair of composite delamination can be achieved with improved microwave processing. Furthermore, microwave welding allows for the construction of a larger structure from smaller components demonstrating the ability to use microwaves for advanced composite manufacturing.

\section{Competing Interests}

The authors declare that there is no conflict of interests regarding the publication of this manuscript.

\section{References}

[1] L. Zong, S. Zhou, N. Sgriccia et al., "A review of microwave assisted polymer chemistry," The Journal of Microwave Power \& Electromagnetic Energy, vol. 38, no. 1, pp. 49-74, 2003.

[2] T. Wang and J. Liu, "A review of microwave curing of polymeric materials," Journal of Electronics Manufacturing, vol. 10, no. 3, pp. 181-189, 2000.

[3] J. Wei and M. C. Hawley, "Utilization of microwaves in processing of polymer composites- past, present and future," Polymeric Materials: Science and Engineering ACS Division of Polymeric Materials: Science \& Engineering, vol. 72, pp. 10-12, 1995.

[4] P. K. D. V. Yarlagadda and T. C. Chai, "An investigation into welding of engineering thermoplastics using focused microwave energy," Journal of Materials Processing Technology, vol. 74, no. 1-3, pp. 199-212, 1998.
[5] E. T. Thostenson and T.-W. Chou, "Microwave processing: fundamentals and applications," Composites Part A: Applied Science and Manufacturing, vol. 30, no. 9, pp. 1055-1071, 1999.

[6] W. I. Lee and G. S. Springer, "Microwave curing of composites," Journal of Composite Materials, vol. 18, no. 4, pp. 387-409, 1984.

[7] A. L. Buxton, "Welding technologies for polymers and composites," in Proceedings of the IMechE Seminar, 2002.

[8] T. H. North and G. Ramarathnam, Welding of Plastics, ASM Handbook: Volume 6: Welding, Brazing, and Soldering, ASM International, 1993.

[9] R. J. Wise and I. D. Froment, "Microwave welding of thermoplastics," Journal of Materials Science, vol. 36, no. 24, pp. 59355954, 2001.

[10] A. P. da Costa, E. C. Botelho, M. L. Costa, N. E. Narita, and J. R. Tarpani, "A review of welding technologies for thermoplastic composites in aerospace applications," Journal of Aerospace Technology and Management, vol. 4, no. 3, pp. 255-265, 2012.

[11] K. R. Paton and A. H. Windle, "Efficient microwave energy absorption by carbon nanotubes," Carbon, vol. 46, no. 14, pp. 1935-1941, 2008.

[12] T. J. Imholt, C. A. Dyke, B. Hasslacher et al., "Nanotubes in microwave fields: light emission, intense heat, outgassing, and reconstruction," Chemistry of Materials, vol. 15, no. 21, pp. 39693970, 2003.

[13] P. Zhihua, P. Jingcui, P. Yanfeng, O. Yangyu, and N. Yantao, "Investigation of the microwave absorbing mechanisms of HiPco carbon nanotubes," Physica E: Low-Dimensional Systems and Nanostructures, vol. 40, no. 7, pp. 2400-2405, 2008.

[14] P. K. Bajpai, I. Singh, and J. Madaan, "Joining of natural fiber reinforced composites using microwave energy: experimental and finite element study," Materials and Design, vol. 35, pp. 596$602,2012$.

[15] K. B. Mani, M. R. Hossan, and P. Dutta, "Thermal analysis of microwave assisted bonding of poly(methyl methacrylate) substrates in microfluidic devices," International Journal of Heat and Mass Transfer, vol. 58, no. 1-2, pp. 229-239, 2013.

[16] M. Kwak, P. Robinson, A. Bismarck, and R. Wise, "Microwave curing of carbon-epoxy composites: penetration depth and material characterisation," Composites Part A: Applied Science and Manufacturing, vol. 75, pp. 18-27, 2015.

[17] P.-C. Sung, T.-H. Chiu, and S.-C. Chang, "Microwave curing of carbon nanotube/epoxy adhesives," Composites Science and Technology, vol. 104, pp. 97-103, 2014.

[18] U. Lopez De Vergara, M. Sarrionandia, K. Gondra, and J. Aurrekoetxea, "Polymerization and curing kinetics of furan resins under conventional and microwave heating," Thermochimica Acta, vol. 581, pp. 92-99, 2014.

[19] D. Y. Wu, S. Meure, and D. Solomon, "Self-healing polymeric materials: a review of recent developments," Progress in Polymer Science, vol. 33, no. 5, pp. 479-522, 2008.

[20] M. R. Kessler, "Self-healing: a new paradigm in materials design," Proceedings of the Institution of Mechanical Engineers, Part G: Journal of Aerospace Engineering, vol. 221, no. 4, pp. 479495, 2007.

[21] S. D. Bergman and F. Wudl, "Mendable polymers," Journal of Materials Chemistry, vol. 18, no. 1, pp. 41-62, 2008.

[22] E. D. Sosa, T. K. Darlington, B. A. Hanos, and M. J. E. O’Rourke, "Multifunctional thermally remendable nanocomposites," Journal of Composites, vol. 2014, Article ID 705687, 12 pages, 2014. 
[23] E. D. Sosa, T. K. Darlington, B. A. Hanos, and M. J. O’Rourke, "Microwave assisted healing of thermally mendable composites," Smart Materials Research, vol. 2015, Article ID 248490, 8 pages, 2015.

[24] F. Ghezzo, D. R. Smith, T. N. Starr et al., "Development and characterization of healable carbon fiber composites with a reversibly cross linked polymer," Journal of Composite Materials, vol. 44, no. 13, pp. 1587-1603, 2010.

[25] J. S. Park, T. Darlington, A. F. Starr, K. Takahashi, J. Riendeau, and $\mathrm{H}$. Thomas Hahn, "Multiple healing effect of thermally activated self-healing composites based on Diels-Alder reaction," Composites Science and Technology, vol. 70, no. 15, pp. 21542159, 2010.

[26] C.-M. Chang and Y.-L. Liu, "Functionalization of multi-walled carbon nanotubes with furan and maleimide compounds through Diels-Alder cycloaddition," Carbon, vol. 47, no. 13, pp. 3041-3049, 2009.

[27] X. Chen, F. Wudl, A. K. Mal, H. Shen, and S. R. Nutt, "New thermally remendable highly cross-linked polymeric materials," Macromolecules, vol. 36, no. 6, pp. 1802-1807, 2003. 

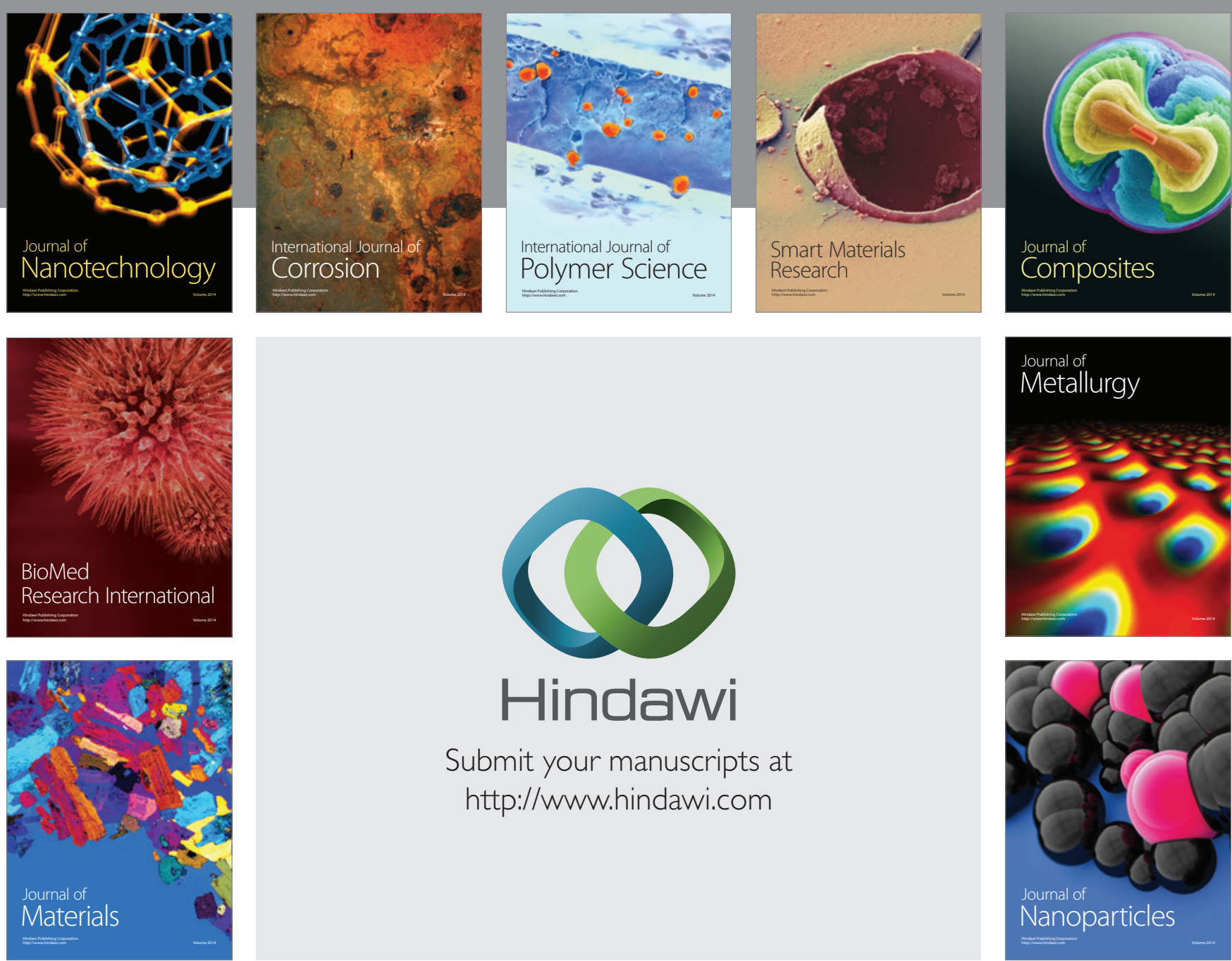

\section{Hindawi}

Submit your manuscripts at

http://www.hindawi.com

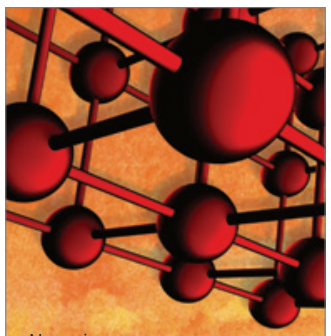

Materials Science and Engineering
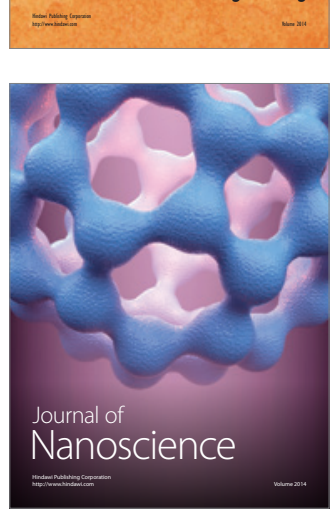
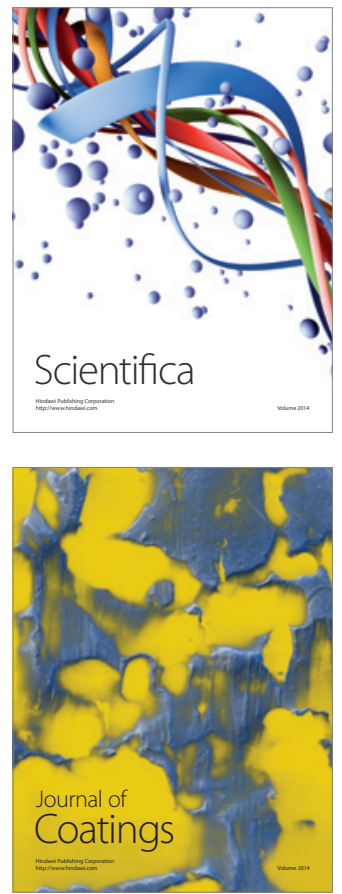
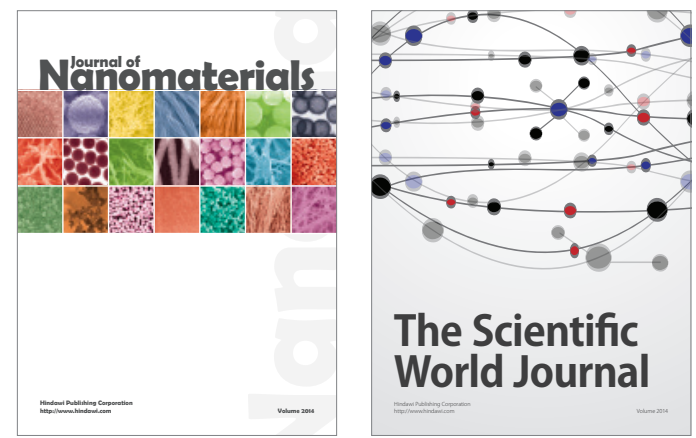

The Scientific World Journal
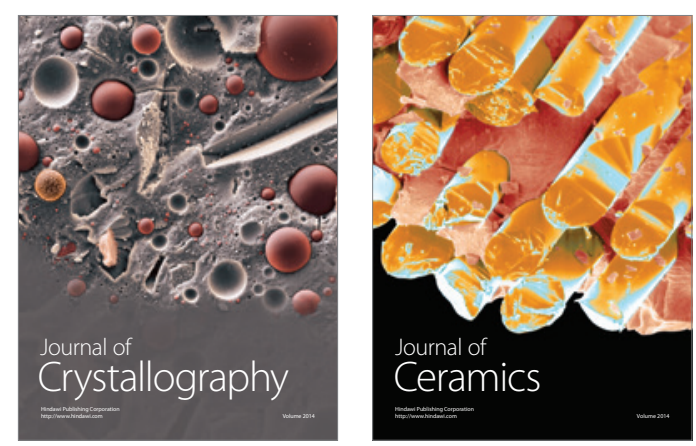
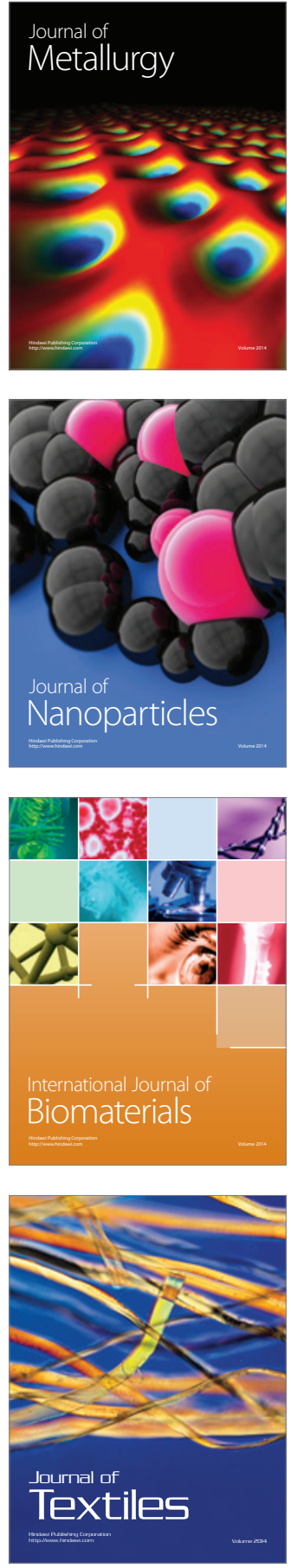